The International Journal of Engineering and Science (IJES)

|| Volume || 6 || Issue || 7 || Pages || PP 22-25 || 2017 ||

ISSN (e): $2319-1813$ ISSN (p): $2319-1805$

\title{
Preparation of Papers for the International Journal of Engineering and Science Friction Stir welding
}

\author{
Ms.Nidhi Pandey ${ }^{1}$, Mr. Rupesh Kumar ${ }^{2}$ \\ ${ }^{1}$ M.Tech. student, Deptt. of Mechanical Engg., Delhi Institute of Technology, Management \& Research \\ Faridabad \\ ${ }^{2}(H O D$ ME) Delhi Institute of Technology, Management \& Research Faridabad
}

\begin{abstract}
Friction welding method is one of the most simple, economical and highly productive method in joining in similar and dissimilar metal. It is widely used in automotive, aircraft and aerospace industrial application. Ceramic metal bonding is the one of the biggest challenge that have faced manufacturers and users over the years because of the inherent differences in the thermal expansion coefficient of the two types of materials. In the present work a ceramic component of AL2o3-YSZ was friction welded to 6061 al alloy. Alumina rods containing 0 and 25 wt \% yttira stabilized zirconia were fabricated by slip casting in plaster of Paris molds and subsequently sintered at 1600 centigrade on the hand the aluminum rods were machine down using a lathe machine to the dimension required. The diameters of the ceramic and metal rods both $15 \mathrm{~mm}$ respectively. Rotational speed of friction welding was between 900 to2500 rpm. Friction pressure was maintained at 7 mpa and friction time was kept constant. The mechanical properties of friction welded al2o3-ysz to 6061 ALLOY were determined with a 4 point bend test and Vickers micro hardness. . The experimental result indicates that the mechanical strength of friction welded al2o3-ysz/6061 al alloy components were obviously affected by joining rotational speed selected.
\end{abstract}

Keywords : friction welding; mechanical properties; ceramic; alumina; zirconia; aluminum; alloy;6061

Date of Submission: 01 July 2017

Date of Accepted: 12 July 2017

\section{Introduction}

Recently, requirements for lightweight and large energy blankets such as for instance aluminium alloys have improved slowly in aerospace, airplane and automotive purposes because of their extra-ordinary energy to fat rate using their opposition attributes in undesirable environments. Friction wake welding (FSW) method is just a stable state joining approach regarded as being the substantial progress in the last two decades. The weld is shaped by the exorbitant deformation of the substance at conditions under their reduction place, hence the technique is just a stable state joining technique. There's number reduction of the substance, therefore FSW has a few benefits within the frequently applied synthesis welding techniques. In the FSW method, parameter variety and software geometry are among the important thing facets that establish the calibre of the manufactured joint. Modifying the prices of various variables, such as for instance welding pace, rotational pace, lean perspective, and green geometry, can decrease the allows exerted from the TMAZ part to the tool. The plastic movement is in charge of obtaining a weld with large tensile energy and less problems and which means software geometry represents an essential position in reaching a supreme quality In FSW, a cylindrical shouldered tool with a profiled pin is rotated and plunged into the joint area between two pieces of sheet or plate material. The parts have to be securely clamped to prevent the joint faces from being forced apart. Frictional heat between the wear resistant welding tool and the workpieces causes the latter to soften without reaching melting point, allowing the tool to traverse along the welding line. The plasticized material, transferred to the trailing edge of the tool pin, is forged through intimate contact with the tool shoulder and pin profile. On cooling, a solid phase bond

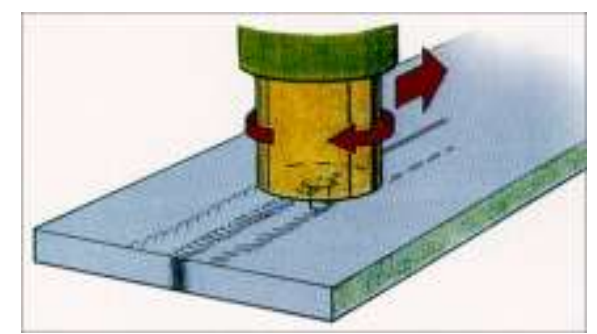

Fig. 1.1 Butt Joint through FSW 


\section{Literature Review}

Liu et al.[1] inside their study report mentioned the friction wake weld capacity of the 2017-T351 aluminum combination and establish perfect welding variables, the relations between welding variables and tensile attributes of the joints. Scientists unearthed that the tensile attributes and fracture places of the bones are somewhat suffering from the welding method parameters. Once the perfect progressive frequency is 0.07 $\mathrm{mm} / \mathrm{rev}$ equivalent to the turning pace of $1500 \mathrm{rpm}$ and the welding pace of $100 \mathrm{~mm} / \mathrm{min}$, the utmost final power of the bones is equal to $82 \%$ that of the bottom material. Although the voids-free bones are fractured near or at the screen involving the weld nugget and the thermo-mechanically influenced region (TMAZ) on the improving area, the fracture happens at the weld middle once the emptiness flaws occur in the joints. Kovacevic (2003) Inside their study friction wake welding (FSW) is just a somewhat new welding method which could have substantial benefits set alongside the combination techniques as follow: joining of conventionally nonfusion weld ready alloys, decreased distortion and increased technical attributes of weld ready alloys bones as a result of genuine solid-state joining of metals. In that report, a three-dimensional design centered on finite aspect examination is employed to review the thermal record and thermo technical method in the butt-welding of aluminum combination 6061-T6. HuseyinUzun et al.[2] investigated that the joining of dissimilar Al 6013-T4 combination and $\mathrm{X} 5 \mathrm{CrNi18}-10$ metal was moved out applying friction wake welding (FSR) technique. Cavaliered et al.[3] investigated the physical and micro architectural attributes of dissimilar 2024 and 7075 aluminum blankets joined by friction mix welding (FSW).

Driver [4] in today's report, a three-dimensional thermo technical design for Friction Mix Welding (FSW) is presented. On the basis of the speed areas classically utilized in water aspects and integrating temperature feedback from the instrument neck and the plastic stress of the majority product, the semi-analytical design may be used to acquire the strains, stress costs, and estimations of the conditions and micro-hardness in the different weld zones.

Marzol et al.[5] recognized a friction wake welding (FSW) method variables package for an AA 6061 metal strengthened with $20 \%$ of $\mathrm{Al} 2 \mathrm{O} 3$ contaminants, and establish qualities of the acquired joints.

Watanabe et al.[6] attempted to butt-weld an aluminum mix menu to a delicate metal menu by friction wake welding, and investigated the consequences of a flag turning rate, the career for the green axis to be put on the tensile power and the microstructure of the joint.

Finding New through literature Review

Following getting literature evaluation discovering that in the literature review various Aluminum combination are utilized and various different proportion of AI are utilized through different state of aspect include in (FSW).of a systematic laboratory investigation on the static behavior of silica sand containing various amount of plastic and non-plastic fines. Ojha and Trivedi (2013) conducted triaxial test on sand fines mixes and reported changes in shear strength parameters.

\section{EXPERIMENTTAL SETUP: EQUIPMENTS USED \\ 1.VERTICAL MILLING MACHINE \\ 2. TENSOMETER \\ 3. HARDNESS TESTING MACHINE}

Fabrication of FSW: Most of the sophisticated welding produced in friction wake welding have now been permitted by the growth of new welding tools. The welding instrument style, including equally their geometry and the product that it's built, IS is crucial to the effective Utilization of the process.

Three kinds of resources were picked in that study. They are:-

Right round

Tapered

Threaded

\section{METHODOLOGY: TAGUCHI METHOD}

Dr. Taguchi of Nippon Phones and Telegraph Business, China is rolling out a technique predicated on "ORTHOGONAL ARRAY" tests gives significantly paid down "deviation" for the test out " ideal adjustments " of get a handle on parameters.

Therefore the union of Style of Studies with optimization of get a handle on variables to acquire BEST effects is accomplished in the Taguchi Method. "Orthogonal Arrays" (OA) offer a couple of well-balanced (minimum) tests and Dr.Taguchi's Signal-to-Noise ratios $(\mathrm{S} / \mathrm{N})$, which are wood features of preferred result, function as aim features for optimization, aid in information examination and forecast of ideal results. 


\section{EXPERIMENTATION PLAN}

In this project research the plan of action was formulated according to the objective of our research

STEP 1 ---- Choosing the appropriate process parameters.

STEP 2 ---- Choosing the appropriate orthogonal array.

STEP 3 ---- Assigning the process parameters proper places in the arrays.

STEP 4 ---- Fabrication of weld joints using different parameters.

STEP 5 ---- Preparation of specimens for testing

STEP 6 ---- Carrying out the various tests

STEP 7 ---- Analyzing the test result data and deduce a conclusion.

SELECTION OF PROCESS PARAMETERS \& THEIR LEVELS

In this research paper we have chosen to optimize three process parameters.

These are:-

Rotor Speed

Tilt Angle

Tool Profile

Table 6.1 Process Parameters

\begin{tabular}{|l|l|l|l|}
\hline Rotor Speed (in rpm) & 950 & 1880 & 2262 \\
\hline Tilt angle( in degree) & 1 & 2 & 3 \\
\hline Tool Profile & Straight cylindrical & Threaded & Tapered \\
\hline
\end{tabular}

TESTING PHASE

Hardness testing: The hardness check is moved out to check the hardness of the weld joint. The hardness could be the way of measuring power of product to fight plastic deformation frequently by indentation each time a compressive power is applied. Hardness is determined by ductility, flexible rigidity, stress etc.

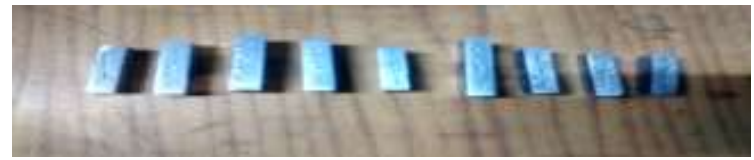

Hardness table

Hardness specimen

Show in table 8.1

Major load $=100 \mathrm{kgfMinor}$ load $=10 \mathrm{kgf}$

Ball dia $=1.5 \mathrm{~mm}$

Table : Hardness Test Readings

\begin{tabular}{|l|l|l|l|l|l|}
\hline $\begin{array}{l}\text { Experi } \\
\text { ment } \\
\text { No. }\end{array}$ & $\begin{array}{l}\text { Hardn } \\
\text { ess } \\
\text { value } \\
\text { (at } \\
\text { base } \\
\text { metal) }\end{array}$ & $\begin{array}{l}\text { Hard } \\
\text { ness } \\
\text { value } \\
\text { (at } \\
\text { edge } \\
\text { of } \\
\text { weld) }\end{array}$ & $\begin{array}{l}\text { Hares } \\
\text { s } \\
\text { value } \\
\text { (at } \\
\text { centre } \\
\text { of } \\
\text { weld) }\end{array}$ & $\begin{array}{l}\text { Hard } \\
\text { ness } \\
\text { value } \\
\text { (at } \\
\text { edge } \\
\text { of } \\
\text { weld) }\end{array}$ & $\begin{array}{l}\text { Hard } \\
\text { ness } \\
\text { value } \\
\text { base at } \\
\text { metal } \\
\text { ) }\end{array}$ \\
\hline 1. & 83 & 73 & 84 & 81 & 83 \\
\hline 2. & 76 & 75 & 78 & 77 & 75 \\
\hline 3. & 98 & 100 & 105 & 102 & 95 \\
\hline 4. & 80 & 92 & 100 & 90 & 88 \\
\hline 5. & 82 & 98 & 102 & 91 & 80 \\
\hline 6. & 84 & 88 & 92 & 90 & 85 \\
\hline 7. & 72 & 86 & 90 & 82 & 75 \\
\hline & & & & & \\
\end{tabular}

\section{TENSILE TEST}

The tensile check of the welded mutual is moved on the tensometer machine. Tensometer is really a system applied to gauge the tensile attributes of components such as for instance their Young's modulus and tensile strength. It is generally a common screening equipment laden with an example between two grabs which are possibly altered physically or immediately to utilize power to the specimen. The equipment operates possibly by operating a prop or by hydraulic ram. 


\section{RESULT AND DISCUSSIONS}

The data collected from the tensile test by tensometer has been graphically shown :-

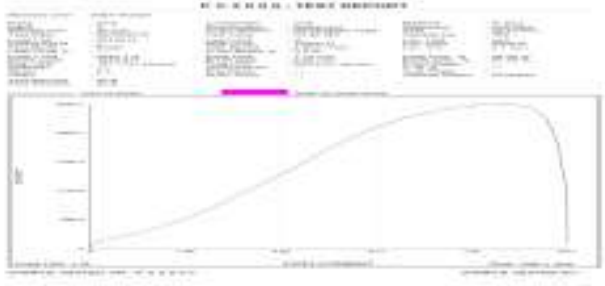

\section{CONCLUSION}

Friction stir welding is now a very trending process. Which is increasingly establing for the fabrication of complex component? It is right to say that FSW has elaborately use of welding in some material application, in particularly in the fabrication joining $2 \mathrm{xxx}$ and $7 \mathrm{xxx}$ alloy for the across pace industry. The improvement making the process attractive include reduce cost, minimize repair need, better properties \& complete automation leading to high level of consistency. The present review demostrated for the Testing report different variation of load and displacement find, Also this variation or the report plot as an graph.

The fact FSW is actually a device instrument process. It's nevertheless, prevailed to make the welding of large energy mix realty.

\section{REFERENCES}

[1] Lei Luo, Dissimilar friction stir welding of Ti-6Al-4V alloy and aluminum alloy employing a modified butt joint configuration: Influences of process variables on the weld interfaces and tensile properties, Materials and Design 53 (2014) 838-848, Received 26 May 2013, Received in revised form 5 July 2013, Accepted 7 July 2013,Available online 18 July 2013.

[2] Hui-jie ZHANG, Hui-jie LIU, Lei YU, Thermal modeling of underwater friction stir welding of high strength aluminum alloy, Trans. Nonferrous Met. Soc. China 23(2013) 1114_1122, Received 23 February 2012; accepted 26 June 2012

[3] P. Cavalierea, R. Nobilea, F.W. Panellaa, A. Squillace. Mechanical and micro structural behavior of 2024-7075 aluminum alloy sheets joined by friction stirs welding. International Journal of Machine Tools \&Manufacture 46 (2006) 588-594.

[4] Driver a, Influence of friction stir welding parameters on the micro structural and mechanical properties of AA 6016-T4 thin welds, Materials and Design 30 (2009) 1913-1921, Received 21 July 2008,Accepted 9 September 2008,Available online 21 September 2008.

[5] Marzol, Material flow and thermo-mechanical conditions during Friction Stir Welding of polymers: Literature review, experimental results and empirical analysis, Materials and Design 59 (2014) 344-351, Received 27 October 2013, Accepted 16 December 2013,Available online 18 February 2014.

[6] Takehiko Watanabe, Hirofumi Takayama, Atsushi Yanagisawa. Joining of aluminum alloy to steel by friction stir welding. Journal of Materials Processing Technology 178 (2006) 342-349

[7] Scialpi, L.A.C. De Filippis, P. Cavaliere. Influence of shoulder geometry on microstructure and mechanical properties of friction stir welded 6082 aluminum alloy. Materials and Design 28 (2007) 1124- 1129.

[8] Ceschini, Effect of welding speed on microstructure and mechanical properties of self-reacting friction stir welded 6061-T6 aluminum alloy, Materials and Design 50 (2013) 872-878, Received 22 January 2013,Accepted 30 March 2013,Available online 11 April 2013.

[9] Hui-jie ZHANG, Hui-jie LIU, Lei YU, Thermal modeling of underwater friction stir welding of high strength aluminum alloy, Trans. Nonferrous Met. Soc. China 23(2013) 1114_1122, Received 23 February 2012; accepted 26 June 2012.

[10] Mario J. Villegas, Jürgen Laudien ,Walter Sielfeld ,Wolf E. Arntz, Macrocystisintegrifolia and Lessoniatrabeculata (Laminariales; Phaeophyceae) kelp habitat structures and associated macrobenthic community oV northern Chile, Helgol Mar Res (2008) 62 (Suppl 1):S33-S43, Received: 6 June 2007 / Revised: 2 November 2007 / Accepted: 9 November 2007 / Published online: 20 December 2007.

[11] S.T. Amancio-Filho, S. Sheikhi,J.F. dos Santos, C. Bolfarini. Preliminary study on the microstructure and mechanical properties of dissimilar friction stir welds in aircraft aluminium alloys 2024-T351 and 6056- journal of materials processing technology.

[12] K. Elangovan, V. Balasubramanian.Influences of tool pin profile and welding speed on the formation of friction stir processing zone in AA2219aluminium alloy. Journal of materials processing technology.

Ms.Nidhi Pandey. " Preparation of Papers for the International Journal of Engineering and Science Friction Stir welding " The International Journal of Engineering and Science (The IJES) 6.7 (2017): 22-25 